Molecular Imaging of Inflammation in Inflammatory Bowel Disease with a Clinically Translatable Dual-Selectin-targeted US Contrast Agent: Comparison with FDG PET/CT in a Mouse Model ${ }^{1}$

Huaijun Wang, MD, PhD

Steven Machtaler, PhD

Thierry Bettinger, $\mathrm{PhD}$

Amelie M. Lutz, MD

Richard Luong, BVSc, DACVP

Philippe Bussat, MSc

Sanjiv S. Gambhir, MD, PhD

François Tranquart, MD, PhD

Lu Tian, PhD

Jürgen K. Willmann, MD
Purpose:

Materials and Methods:

Results:

1 From the Department of Radiology, Molecular Imaging Program at Stanford (H.W., S.M., A.M.L., S.S.G., J.K.W.), Department of Comparative Medicine (R.L.), and Department of Health, Research \& Policy (L.T.), Stanford University School of Medicine, 300 Pasteur Dr, Room H1307; Stanford, CA 94305-5621; and Bracco Suisse, Geneva, Switzerland (T.B., P.B., F.T.). From the 2012 RSNA Annual Meeting. Received November 27, 2012; revision requested December 21; revision received January 2, 2013; accepted January 4; final version accepted January 7. H.W. supported by the Stanford Dean Fellowship award. J.K.W. supported in part by the Howard S. Stern Research Grant of the Society of Gastrointestinal Radiologists. Address correspondence to J.K.W. (e-mail: willmann@stanford.edu).
To develop and test a molecular imaging approach that uses ultrasonography (US) and a clinically translatable dual-targeted (P- and E-selectin) contrast agent $\left(\mathrm{MB}_{\text {Selectin }}\right)$ in the quantification of inflammation at the molecular level and to quantitatively correlate selectin-targeted US with fluorodeoxyglucose (FDG) combined positron emission tomography (PET) and computed tomography (CT) in terms of visualization and quantification of different levels of inflammation in a murine acute colitis model.

Animal studies were approved by the Institutional Administrative Panel on Laboratory Animal Care at Stanford University. $\mathrm{MB}_{\text {Selectin }}$ was developed by covalently binding an analog of the naturally occurring binding ligand $\mathrm{P}$-selectin glycoprotein ligand 1 fused to a human fragment crystallizable(or Fc) domain onto the lipid shell of perfluorobutane and nitrogen-containing MBs. Binding specificity of $\mathrm{MB}_{\text {Selectin }}$ was assessed in vitro with a flow chamber assay and in vivo with a chemically induced acute colitis murine model. US signal was quantitatively correlated with FDG uptake at PET/CT and histologic grade. Statistical analysis was performed with the Student $t$ test, analysis of variance, and Pearson correlation analysis.

$\mathrm{MB}_{\text {Selectin }}$ showed strong attachment to both human and mouse $\mathrm{P}$ - and E-selectin compared with $\mathrm{MB}_{\text {Control }}$ in vitro $(P \leq .002)$. In vivo, US signal was significantly increased $(P<.001)$ in mice with acute colitis $(173.8$ arbitrary units [au] \pm 134.8 [standard deviation]) compared with control mice $(5.0 \mathrm{au} \pm 4.5)$. US imaging signal strongly correlated with FDG uptake on PET/CT images $(\rho=0.89, P<.001)$. Ex vivo analysis enabled confirmation of inflammation in mice with acute colitis and high expression levels of $\mathrm{P}$ - and E-selectin in mucosal capillaries $(P=.014)$.

Conclusion: US with $\mathrm{MB}_{\text {Selectin }}$ specifically enables detection and quantification of inflammation in a murine acute colitis model, leveraging the natural pathway of leukocyte recruitment in inflammatory tissue. US imaging with $\mathrm{MB}_{\text {Selectin }}$ correlates well with FDG uptake at PET/CT imaging.

${ }^{\circ}$ RSNA, 2013

Supplemental material: http://radiology.rsna.org/lookup /suppl/doi:10.1148/radiol.13122509/-/DC1 
nflammatory bowel disease (IBD) is a complex group of diseases that includes Crohn disease and ulcerative colitis; it involves changes in mucosal immunity and gastrointestinal physiology and affects approximately 1.4 million patients in North America $(1,2)$. Although the causes may vary from genetic susceptibility to an abnormal immune response to commensal gut bacteria, all causes share similar abnormalities, including infiltration of leukocytes, production of inflammatory mediators, and tissue remodeling that ultimately leads to ulcerations and bowel injury (3). Accurate monitoring of disease activity to optimize therapeutic interventions with minimal side effects is one of the greatest challenges in the appropriate clinical management of IBD. Since patients with IBD usually require multiple follow-up examinations,

\section{Advances in Knowledge}

- A dual-targeted clinically translatable US contrast agent $\left(\mathrm{MB}_{\text {Selectin }}\right)$ with an analog of the naturally occurring binding ligand P-selectin glycoprotein ligand 1 fused to a human Fc domain demonstrates strong and specific attachment to both human and mouse $\mathrm{P}$ - and E-selectin in vitro.

- In vivo $\mathrm{US}$ imaging with $\mathrm{MB}_{\text {Selectin }}$ can be used to accurately assess inflammation of various degrees in a chemically induced murine model of colitis compared with histologic scoring.

- In vivo US imaging with $\mathrm{MB}_{\text {Selectin }}$ correlates well with fluorodeoxyglucose uptake on PET/CT images $(\rho=0.89, P<.001)$.

- Ex vivo analysis of inflamed colon tissue at day 1 after colitis induction shows high $\mathrm{P}$ - and E-selectin expression $(34.2 \% \pm 18.9$ [standard deviation] of vessels positive for P-selectin, $32.1 \% \pm 26.2$ of vessels positive for E-selectin) mostly in capillaries in close proximity to immune cells present in the submucosa and base of the mucosa. often over many years, monitoring should be noninvasive and, above all, patient friendly. A simple technique that meets all these requirements is not available.

Recently, molecular imaging with ultrasonography (US) and contrast microbubbles (MBs) that can be targeted to molecular markers of inflammation has been suggested as a promising noninvasive imaging approach with which to monitor inflammation in patients with IBD at the molecular level $(4,5)$. Molecularly targeted US imaging combines the advantages of US, including availability, relatively low cost, realtime capabilities, and lack of ionizing radiation (which is particularly important in longitudinal monitoring of young patients), with the advantages of molecular imaging to visualize and quantify molecules that are differentially expressed in various diseases. The adhesion molecules $\mathrm{P}$ - and E-selectin are highly expressed on inflamed vasculature in patients with active IBD (6-8). Both selectins are involved in the leukocyte adhesion cascade, which includes capture, rolling, and adhesion of leukocytes before transmigration into the inflamed tissue. P-selectin glycoprotein ligand 1, expressed on the surface of leukocytes, is the natural ligand of both P- and E-selectin. A truncated peptide of P-selectin glycoprotein ligand 1 , comprising the first 47 amino acids and fused to a human fragment crystallizable (or Fc) domain (recombinant $\mathrm{P}$-selectin glycoprotein ligand immunoglobulin G [rPSGL-Ig], also known as YSPSL), preserves the binding function of the natural ligand and is currently being evaluated as an anti-inflammatory drug in clinical trials $(9,10)$. Since rPSGL-Ig is currently

\section{Implication for Patient Care}

- $\mathrm{MB}_{\text {Selectin }}$ attachment uses the natural pathway of leukocyte recruit ment to inflamed tissue and can be further developed as a noninvasive clinical imaging biomarker for inflammation quantification in patients with inflammatory bowel disease with US imaging. undergoing clinical testing as a therapeutic agent with favorable safety profiles (11), it is an attractive binding ligand with which to develop a clinically translatable molecularly targeted contrast agent for US imaging of inflammation, thereby leveraging the natural pathway of leukocyte recruitment in inflammatory tissue as a biomarker of inflammation $(12,13)$.

The purpose of this study was to develop and test a molecular imaging approach that uses US and a recently develped clinically translatable dualtargeted ( $\mathrm{P}$ - and E-selectin) contrast agent $\left(\mathrm{MB}_{\text {Selectin }}\right)$ in the quantification of inflammation at the molecular level and to quantitatively correlate selectintargeted US with fluorodeoxyglucose (FDG) combined positron emission tomography (PET) and computed tomography (CT) in terms of visualization and quantification of different levels of inflammation in a murine acute colitis model.

\author{
Published online before print \\ 10.1148/radiol.13122509 Content codes: GI MI \\ Radiology 2013; 267:818-829 \\ Abbreviations: \\ FDG = fluorodeoxyglucose \\ $\mathrm{IBD}=$ inflammatory bowel disease \\ $\mathrm{ID}=$ injected dose \\ $\mathrm{MB}=$ microbubble \\ $\mathrm{MB}_{\text {Control }}=$ control $\mathrm{MB}$ \\ $\mathrm{MB}_{\text {Selectin }}=\mathrm{P}$ - and E-selectin-targeted MB \\ $\mathrm{rba}=$ rate of $\mathrm{MB}$ accumulation \\ rPSGL-Ig = recombinant P-selectin glycoprotein ligand \\ immunoglobulin $\mathrm{G}$ \\ TNBS $=2,4,6$-trinitrobenzenesulfonic acid
}

\section{Author contributions:}

Guarantors of integrity of entire study, H.W., J.K.W.; study concepts/study design or data acquisition or data analysis/interpretation, all authors; manuscript drafting or manuscript revision for important intellectual content, all authors; approval of final version of submitted manuscript, all authors; literature research, H.W., T.B., A.M.L., J.K.W.; experimental studies, H.W., S.M., T.B., R.L., P.B., J.K.W.; statistical analysis, H.W., L.T., J.K.W.; and manuscript editing, H.W., S.M., J.K.W.

\section{Funding:}

This research was supported by the National Institutes of Health (grants DK56339 and R01DK092509-01A1).

Conflicts of interest are listed at the end of this article.

See also Science to Practice in this issue. 


\section{Materials and Methods}

Bracco Suisse provided the clinically translatable contrast agent used in this study. Authors who are not employees of or consultants for Bracco Suisse had control over inclusion of any data and information that might have presented a conflict of interest for authors who are employees of or consultants for Bracco Suisse.

\section{Design of MB}

A clinically translatable dual-targeted US contrast agent $\left(\mathrm{MB}_{\text {Selectin }}\right)$ was designed by using rPSGL-Ig as a binding ligand. Nontargeted $\mathrm{MB}_{\text {Control }}$ was prepared with the same technique but without coupling of the binding ligand rPSGL-Ig to the MB shell. The rPSGLIg-conjugated liposomes were also synthesized and used for competition studies. Details of the MB and liposome synthesis are provided in Appendix E1 (online).

\section{Flow Chamber Binding Assay for $\mathbf{M B}_{\text {Selectin }}$}

Binding behavior of $\mathrm{MB}_{\text {Selectin }}$ to recombinant mouse or human $\mathrm{P}$ - and E-selectin proteins was tested under flow shear stress conditions in a flow chamber setting. Details of this assay are provided in Appendix E1 (online).

Binding of both MB types was analyzed in five randomly selected fields of view (each was $183 \times 137 \mu \mathrm{m}$ ) per coverslip, and the number of bound MBs was determined by using software (Analysis Five; Soft Imaging Systems, Münster, Germany). Average bound MB numbers were divided by 10 (10-minute observation time) to calculate the rate of MB accumulation per minute (rba). The same experiments were performed with each coating. Five coverslips were used for each experiment.

\section{Mouse Model of IBD}

Animal studies were approved by the Institutional Administrative Panel on Laboratory Animal Care at Stanford University. A total of 92 male BALB/c mice (Charles River Laboratories, Wilmington, Mass) (age range, 6-8 weeks; weight range, 20-25 g) were imaged in this study and randomly divided into two groups. In the colitis group $(n=73)$, acute colitis was induced, as described previously (14). Mice were gas anesthetized with $2 \%$ isoflurane in $2 \mathrm{~L}$ of oxygen per minute. A polyethylene catheter (PE90; Becton Dickinson, Sparks, Md) was carefully cannulated with lubrication into the colon, and the tip of the catheter was inserted until it was about $4 \mathrm{~cm}$ proximal to the anus. Contact sensitizing allergen 2,4,6-trinitrobenzenesulfonic acid (TNBS) (2.5 $\mathrm{mg}$ in $50 \%$ ethanol; total injection volume, $100 \mu \mathrm{L}$ ) was administered into the lumen of the colon via the catheter, and the colon was exposed for 15 minutes with TNBS, as described previously (14). In this model, ethanol breaks the mucosal barrier to enable haptenization of TNBS with colonic autologous or microbiota proteins, rendering them immunogenic to the host immune system (12). This causes a CD4+ $\mathrm{T}$ cell-dependent mucosal immune response with subsequent transmural cellular infiltration that, in some cases, is associated with granulomas resembling Crohn disease (15). The mucosal immune response can vary between mice, resulting in different degrees of inflammation among animals and thereby allowing assessment of $\mathrm{MB}_{\text {Selectin }}$ with US imaging over a broad spectrum of inflammation grades in our study $(14,16,17)$. In the control group $(n=19)$, only saline was injected into the colon via the catheter.

\section{In Vivo Imaging of Mice}

A total of 70 mice (51 with colitis, 19 controls) were included for an intraanimal cross-modality comparison between selectin-targeted US and FDG $\mathrm{PET} / \mathrm{CT}$, and both imaging examinations were performed on the same day within 3 hours of each other. The control mice were scanned and then humanely sacrificed on the same day for ex vivo analysis of the colon. The mice with colitis were scanned at either day $1(n=27)$ or day $5(n=24)$ after colitis induction; scanning was followed by harvesting of the colon for ex vivo analysis. This experimental design yielded a spectrum of inflammation grades at days 1 and 5 after TNBS administration, with ex vivo correlation of imaging signals (mice with TNBSinduced colitis spontaneously recover within several days of injection, with a lower inflammation grade at day 5 compared with that at day 1) $(14,16,17)$. Figure 1 summarizes the study design. A minimum of 18 mice per group was required to have at least $80 \%$ power to detect a minimum mean group difference of one standard deviation at a significance level of .05 .

US imaging.-US imaging with $\mathrm{MB}_{\text {Selectin }}$ was performed in all 70 mice with dedicated small-animal US equipment (Vevo 2100; VisualSonics, Toronto, Ontario, Canada) (lateral and axial resolution, 165 and $75 \mu \mathrm{m}$, respectively; focal length, $8 \mathrm{~mm}$; transmit power, 10\%; mechanical index, 0.2; dynamic range, $35 \mathrm{~dB}$ ) and a dedicated small-animal transducer (MS250; VisualSonics) (center frequency, $21 \mathrm{MHz}$ ). Imaging was performed with mice in the supine position. Fifteen minutes before US scanning, $2 \mu \mathrm{g}$ of atropine was injected subcutaneously to reduce bowel motility $(18,19)$. After mice were positioned on the US scanning table and gas anesthetized with $2 \%$ isoflurane in $2 \mathrm{~L}$ of oxygen per minute, the colon was first localized in B mode $3 \mathrm{~cm}$ from the anus by using an electronic caliper available on the machine. Transverse US images were then acquired in the contrast mode 4 minutes after intravenous bolus injection of $5 \times 10^{7} \mathrm{MB}_{\text {Selectin }}$ via a catheter in the tail vein, as described previously $(5,20)$. In brief, 480 imaging frames were acquired, which enabled us to detect signal from both molecularly attached targeted MB and freely circulating MB. This was followed by a 1-second destruction pulse (transmit power, 100\%; mechanical index, 0.63) to destroy all MBs in the same field of view. Immediately after the destruction pulse, another 480 frames were obtained to acquire the signal from freely circulating MBs only. These data were used to compare US signal with FDG uptake at PET/CT.

To further demonstrate specific binding of $\mathrm{MB}_{\text {Selectin }}$ to the targets $\mathrm{P}$ and E selectin in vivo, an additional 10 mice with colitis (day 1) were injected with both $\mathrm{MB}_{\text {Selectin }}$ and $\mathrm{MB}_{\text {Control }}$ in random 
Figure 1

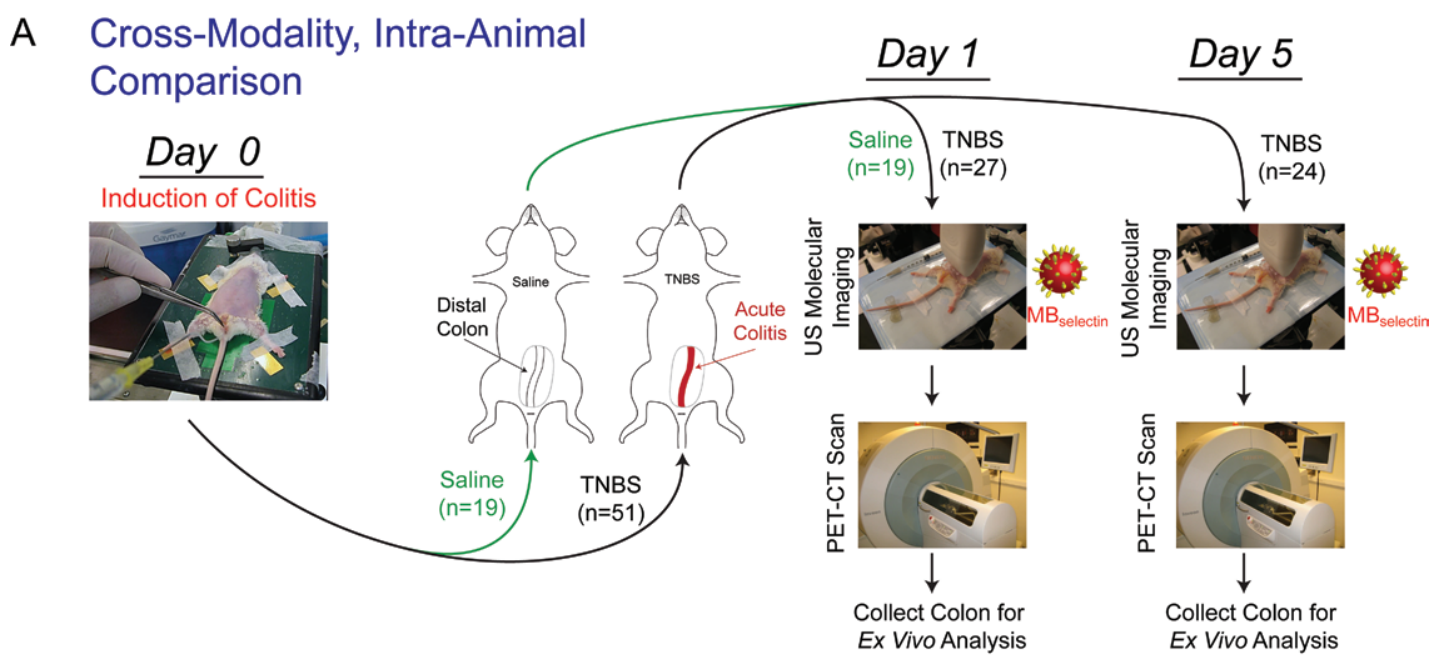

B

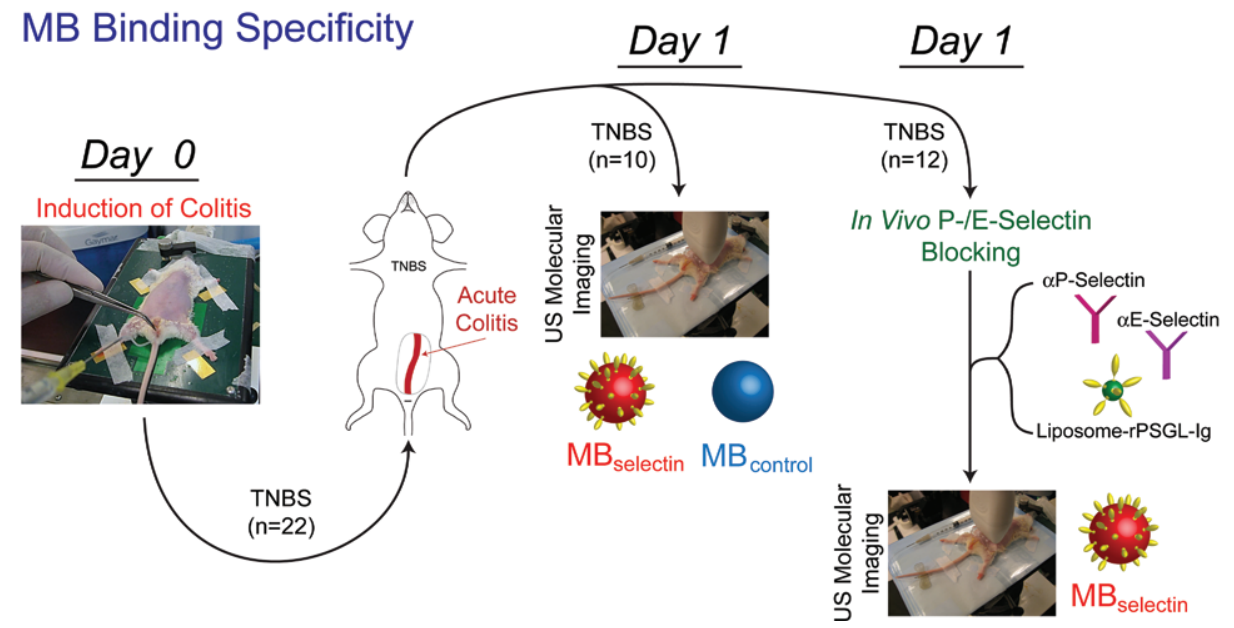

Figure 1: Overview of experimental design for in vivo selectin-targeted US and FDG PET/CT. A, Cross-modality intraanimal comparison between US and PET/CT was performed in control mice and those with TNBS-induced colitis. After imaging, colon tissues were harvested for ex vivo analysis, including inflammation grading and quantitative immunofluorescence of $\mathrm{P}$ - and E-selectin expression. $B$, In additional colitis mice, binding specificity of $\mathrm{MB}_{\text {Selectin }}$ was assessed by using nontargeted $\mathrm{MB}_{\text {Control }}$ and in vivo blocking experiments.

order $(100-\mu \mathrm{L}$ saline bolus containing either $5 \times 10^{7} \mathrm{MB}_{\text {Selectin }}$ or $5 \times 10^{7}$ $\mathrm{MB}_{\text {Control }}$ ) via the tail vein catheter. To allow MB from previous injections to clear, bolus injections were separated by 30 minutes (21). In vivo antibody blocking experiments were performed in an additional eight mice with colitis (day 1). After imaging with $\mathrm{MB}_{\text {Selectin }}$ and a 30-minute pause for clearance of the MB, $125 \mu \mathrm{g}$ of a rat antimouse P-selectin antibody (clone RB40.34; BD Pharmingen, San Diego, Calif) $(n=4)$ or $125 \mu \mathrm{g}$ of a rat antimouse E-selectin antibody (clone 10E9.6; BD Pharmingen) $(n=4)$ was injected via a tail vein in random order. After $30 \mathrm{mi}-$ nutes to allow the first antibody to circulate, US imaging of the same colon segment with $\mathrm{MB}_{\text {Selectin }}$ was repeated. Another 30 minutes later, sequential blocking with the second antibody was performed, followed by US imaging with $\mathrm{MB}_{\text {Selectin }}$. In another four mice with colitis (day 1), an in vivo competition assay with rPSGL-Ig-conjugated liposomes was performed. After imaging with $\mathrm{MB}_{\text {Selectin }}$ and the 30-minute pause for clearance of $\mathrm{MB}, 2.2 \mathrm{nmol}$ of control nontargeted liposomes were injected via the tail vein catheter. After 30 minutes, US imaging with $\mathrm{MB}_{\text {Selectin }}$ was repeated in the same colon location. After 30 more minutes, rPSGLIg-conjugated liposomes at the same dose $(2.2 \mathrm{nmol})$ were injected via the tail vein; this was followed by US imaging with $\mathrm{MB}_{\text {Selectin }}$ after 30 additional minutes. 
FDG PET/CT imaging protocol.Within 3 hours after US imaging, FDG $\mathrm{PET} / \mathrm{CT}$ was performed in all 70 mice with a dedicated small-animal PET/CT system (Inveon; Siemens, Knoxville, Tenn), as described previously (22). Details on PET/CT imaging are provided in Appendix E1 (online).

Confocal microscopy of $M B s$ and blocking liposomes. - To further prove that $\mathrm{MB}_{\text {Selectin }}$ binds to inflamed vessels in the colon wall with direct microscopic visualization, $\mathrm{MB}_{\text {Selectin }}$ and rPSGL-Igconjugated liposomes were labeled fluorescently and injected intravenously into additional mice with colitis (day 1 , $n=5$; day $5, n=2$ ) and control mice $(n=5)$. For the in vivo competition assay, labeled rPSGL-Ig-conjugated liposomes were injected first and allowed to circulate for 30 minutes. Then, labeled $\mathrm{MB}_{\text {Selectin }}$ was injected and colon tissues were harvested. Details on fluorescent labeling of $\mathrm{MB}$ and liposomes and on confocal microscopy are provided in Appendix E1 (online).

\section{In Vivo Imaging Analysis}

All US data sets were analyzed off-line in random order by one radiologist (H.W.) with 2 years of experience in US image analysis of the murine colon using the aforementioned dedicated workstation with commercially available software. The reader was blinded to the animal group (colitis vs control, day 1 vs day 5) and to MB types $\left(\mathrm{MB}_{\text {Selectin }}\right.$ vs $\left.\mathrm{MB}_{\text {Control }}\right)$. A region of interest (mean area, $4.6 \mathrm{~mm}^{2}$; range, $4-8$ $\mathrm{mm}^{2}$ ) was drawn over the colon wall on transverse images (obtained $3 \mathrm{~cm}$ from the anus). The magnitude of imaging signal from the attached MB was measured by calculating an average for preand postdestruction imaging signals and by subtracting the average postdestruction signal from the average predestruction signal, as described previously (23). Images representing the adherent MB were displayed as a color-coded signal overlaid on B-mode images.

The same blinded reader performed quantitative analysis of FDG uptake with commercially available Inveon Research Workplace software (version 2.2; Siemens Healthcare Molecular
Imaging). Briefly, the PET and CT images were automatically coregistered. With the cross-reference coronal and sagittal images, a volume of interest (mean volume, $4.4 \mathrm{~mm}^{3}$; range, $3.2-$ $7.1 \mathrm{~mm}^{3}$ ) was drawn over the colon wall $3 \mathrm{~cm}$ from the anus on transverse PET images, surrounding the colon lumen, which was filled with diatrizoate meglumine and diatrizoate sodium (Gastroview; Mallinckrodt, St Louis, Mo) and shown as a highly attenuated area, as described previously (22). In all animals, measurements were obtained at the same location $3 \mathrm{~cm}$ from the anus, and partial volume correction was not performed. By using a calibration constant obtained from scanning a cylindrical phantom in the scanner, inflammatory tissue uptake of FDG was measured as the mean percentage of decay-corrected injected dose (ID) per gram, with the assumption that the tissue density was $1 \mathrm{~g} / \mathrm{cm}^{3}$.

\section{Ex Vivo Analysis of Colon Tissue}

After imaging, animals were sacrificed, and colon tissues were harvested $3 \mathrm{~cm}$ from the anus (at the level of US and PET/CT image analysis). Tissues were fixed in $4 \%$ paraformaldehyde overnight at $4^{\circ} \mathrm{C}$ and then cryopreserved in a $30 \%$ sucrose solution. Samples were then placed in optimal cutting temperature media and frozen, after which 10 - $\mu$-thick slices were obtained by using a cryomicrotome. Expression of $\mathrm{P}$ - and E-selectin was visualized by using standard immunofluorescence procedures and quantified as detailed in Appendix E1 (online).

For hematoxylin-eosin staining, colon tissues were embedded in paraffin, cut into $10-\mu m$-thick slices, and stained with hematoxylin-eosin according to standard protocols (5). The histologic grade of inflammation was scored blindly by one pathologist (R.L.) using a standardized histologic scoring system (score range, 0-4), as described previously $(24,25)$.

\section{Statistical Analysis}

Data were reported as mean \pm standard deviation. For flow chamber experiments, two-sample Student $t$ tests were used to compare binding specificity to mouse $\mathrm{P}$ - and E-selectin and human $\mathrm{P}$ - and E-selectin between $\mathrm{MB}_{\mathrm{S}}$ and $\mathrm{MB}_{\text {Conrol }}$. Similarly, the Student $t$ test was used to compare immunofluorescence staining for $\mathrm{P}$ - and E-selectin expression levels between control and colitis tissues at days 1 and 5 and between colitis tissues at days 1 and 5 . For these three pairwise comparisons, a Bonferroni correction of the $P$ value was applied $(P \leqslant .017$ indicated a significant difference). Furthermore, analysis of variance was performed to compare US and PET measurements among three groups: the control group, the colitis group at day 1 , and the colitis group at day 5 . The postoverall comparison (based on the $F$ test) analysis for three pairwise comparisons was based on Tukey adjustment. The Pearson correlation coefficient between US and PET from the same mice was estimated. The significance level was set at .05. All statistical analyses were performed by using statistical software (R software, version 2.10.1; R Foundation for Statistical Computing, Vienna, Austria).

\section{Results}

\section{Flow Chamber Binding Assay}

The binding specificity of $\mathrm{MB}_{\text {Selectin }}$ to both $\mathrm{P}$ - and E-selectin was assessed by using a flow chamber setting (Fig E1, Appendix E1 [online]), and the cross-reactivity of $\mathrm{MB}_{\text {Selectin }}$ with both murine and human P- and E-selectin was confirmed (Table, Fig E1, Appendix E1 [online]). Binding rates of $\mathrm{MB}_{\text {Selectin }}$ to recombinant murine and human P-selectin were significantly higher (murine P-selectin: $5.8 \mathrm{rba} / \mathrm{min}$ $\pm 0.4, P<.001$; human P-selectin: 7.2 $\mathrm{rba} / \mathrm{min} \pm 0.5, P=.002)$ than those of $\mathrm{MB}_{\text {Control }}$ to recombinant murine and human P-selectin (murine P-selectin, $0.1 \mathrm{rba} / \mathrm{min} \pm 0.01$; human P-selectin, $0.3 \mathrm{rba} / \mathrm{min} \pm 0.03)$ and significantly lower (murine P-selectin: $0.1 \mathrm{rba} / \mathrm{min} \pm$ 0.09, $P<.001$; human P-selectin: 0.1 $\mathrm{rba} / \mathrm{min} \pm 0.01, P=.002)$ than those in blocking experiments (Table). Similarly, attachment of $\mathrm{MB}_{\text {Selectin }}$ to murine $(6.2$ $\mathrm{rba} / \mathrm{min} \pm 0.2)$ and human $(5.0 \mathrm{rba} /$ 


\section{Figure 2}
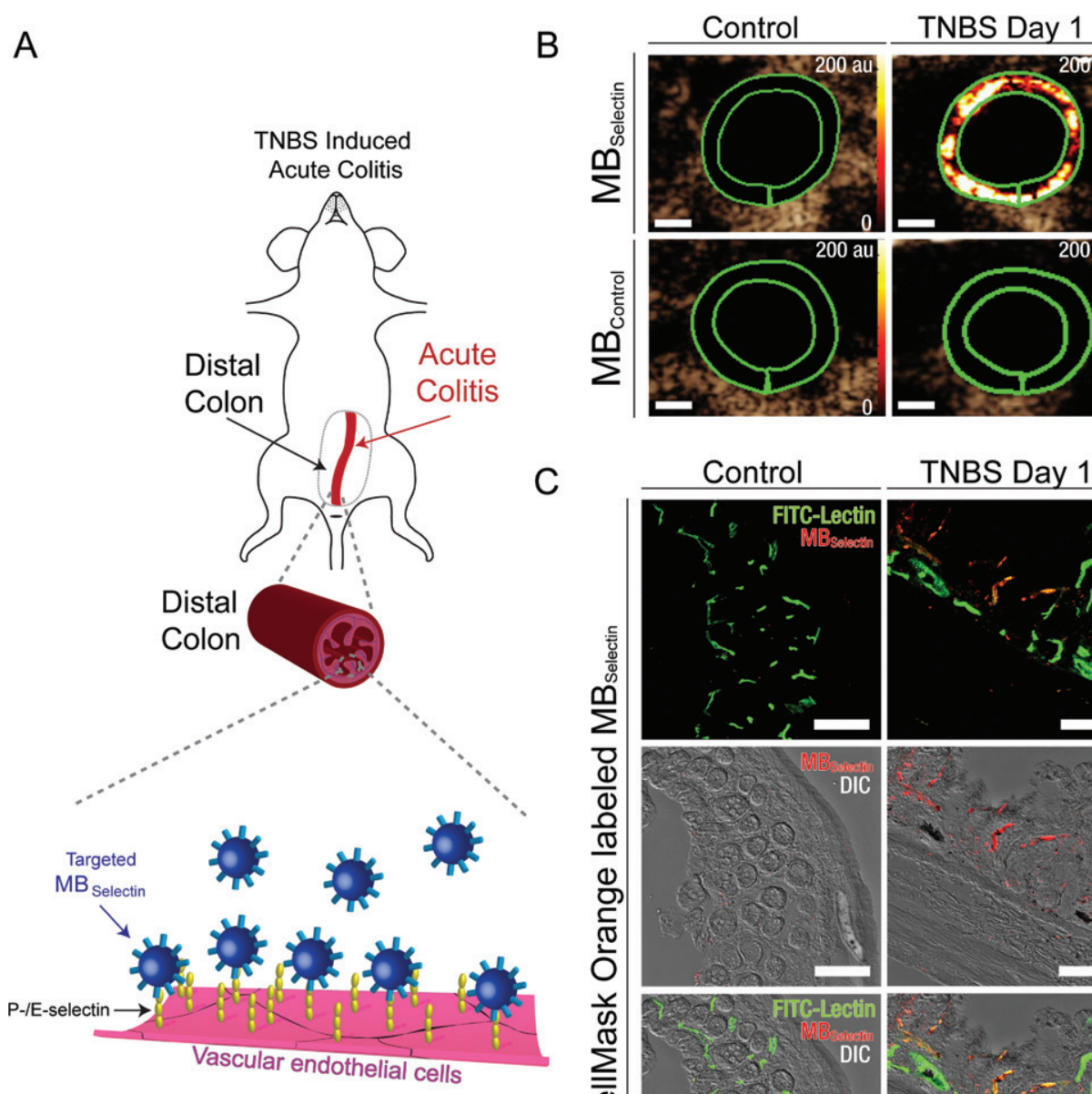

TNBS Day 5
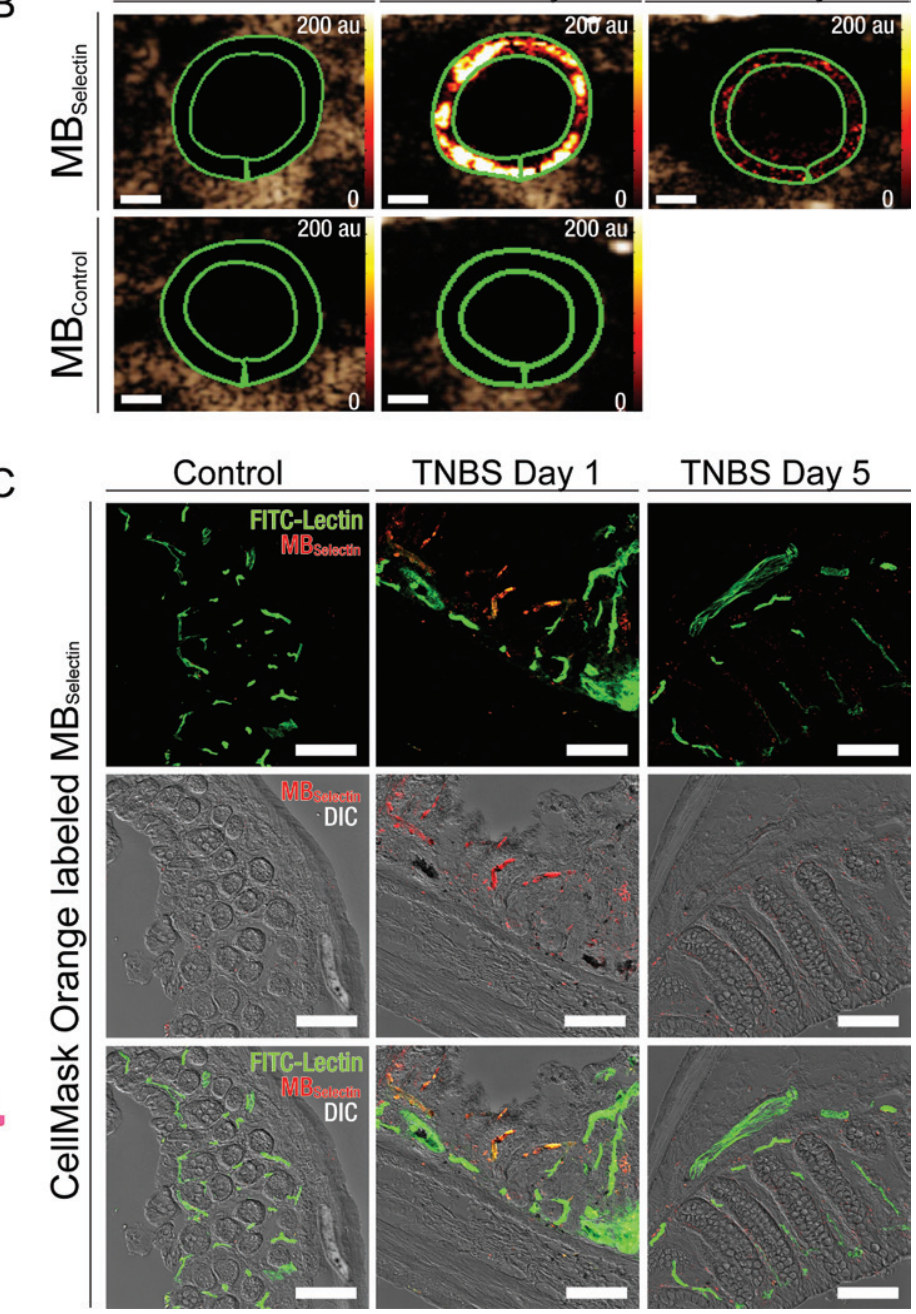

Figure 2: Selectin-targeted US imaging and MB localization in the colon of mice after induction of acute colitis. $A$, Schematic representation of $\mathrm{MB}_{\text {Selectin }}$ binding to the inflamed capillaries within the colon after TNBS-induced colitis. $B$, Representative transverse US images of the colon in a control mouse (left) and experimental mice at day 1 (middle) and day 5 (right) after TNBS administration with $\mathrm{MB}_{\text {Selectin }}$ (top) and $\mathrm{MB}_{\text {control }}$ (bottom). Green ring corresponds to region of interest (scale bar $=1 \mathrm{~mm}$ ). C, Representative confocal micrographs overlaid on differential interference contrast images show accumulation of fluorescently labeled $\mathrm{MB}_{\text {Selectin }}$ (red) in mucosal capillaries (green) in a day-1 TNBS-induced colitis mouse (middle) but not in noninflamed colon tissue in a control mouse (left) and only minimally in a day-5 TNBSinduced colitis mouse (right) (scale bar $=100 \mu \mathrm{m}$ ).

$\min \pm 0.2)$ E-selectin was significantly higher $(P<.001)$ than attachment of $\mathrm{MB}_{\text {Control }}$ to murine $(0.3 \mathrm{rba} / \mathrm{min} \pm$ $0.09)$ and human $(0.2 \mathrm{rba} / \mathrm{min} \pm 0.03)$ E-selectin. Attachment of $\mathrm{MB}_{\text {Selectin }}$ to both murine $(0.6 \mathrm{rba} / \mathrm{min} \pm 0.2)$ and human $(0.2 \mathrm{rba} / \mathrm{min} \pm 0.01)$ E-selectin after blocking was significantly lower $(P$ $<.001$ ) (Table, Fig E1, Appendix E1 [online]). $\mathrm{MB}_{\text {Selectin }}$ firmly adhered to the coating of recombinant proteins.
In Vivo US Imaging with $M_{\text {Selectin }}$ and Assessment of MB Attachment in Tissue

In control mice, there was minimal signal in the bowel wall with both MBControl (mean, 4.7 arbitrary units [au] \pm 8.2; range, 0.3-14.1 au) and $\mathrm{MB}_{\text {Selecti }}$ (mean, 5.0 au \pm 4.5 ; range, $0.2-15.0$ au; $P=.90)($ Fig $2, B)$. In contrast, the signal with $\mathrm{MB}_{\text {Selectin }}$ significantly increased $(P<.001)$, on average, 35-fold to 173.8 au \pm 134.8 (range,
35.6-450.4 au) at day 1 after induction of acute colitis (Fig 2, B) and significantly decreased $(P<.001)$ in mice with lower-grade inflammation at day 5 after induction of acute colitis $(9.2 \mathrm{au}$ \pm 7.7; range, 0.1-29.7 au) (Fig 2, B). Administration of $\mathrm{MB}_{\text {Control }}$ in mice with acute colitis at day 1 resulted in significantly lower $(P<.001)$ imaging signal (mean, 19.0 au \pm 9.2; range, 3.0-42.8 au) compared with that of $\mathrm{MB}_{\text {Selectin }}$ at 


\begin{tabular}{|c|c|c|c|}
\hline \multicolumn{4}{|c|}{$\begin{array}{l}\text { Attachment of } M_{\text {Selectin }} \text { and } M B_{\text {controt }} \text { to Recombinant Mouse or Human P- and } \\
\text { E-Selectin Proteins under Dynamic Conditions in a Flow Chamber }\end{array}$} \\
\hline Ligand & $\mathrm{MB}_{\text {Selectin }}$ (rba/min) & $\mathrm{MB}_{\text {Control }}(\mathrm{rba} / \mathrm{min})$ & $\mathrm{MB}_{\text {Selectin }}$ after Blocking (rba/min) \\
\hline Mouse P-selectin & $5.8 \pm 0.4$ & $0.1 \pm 0.01$ & $0.1 \pm 0.09^{\star}$ \\
\hline Human P-selectin & $7.2 \pm 0.5$ & $0.3 \pm 0.03$ & $0.1 \pm 0.01$ \\
\hline Mouse E-selectin & $6.2 \pm 0.2$ & $0.3 \pm 0.09$ & $0.6 \pm 0.2$ \\
\hline Human E-selectin & $5.0 \pm 0.2$ & $0.2 \pm 0.03$ & $0.2 \pm 0.01$ \\
\hline
\end{tabular}

Note.-Data are mean \pm standard deviation.

${ }^{*}$ With liposome blocking, $\mathrm{MB}_{\text {Selectin }}$ after blocking was $0.1 \pm 0.03$.

\section{Figure 3}

A
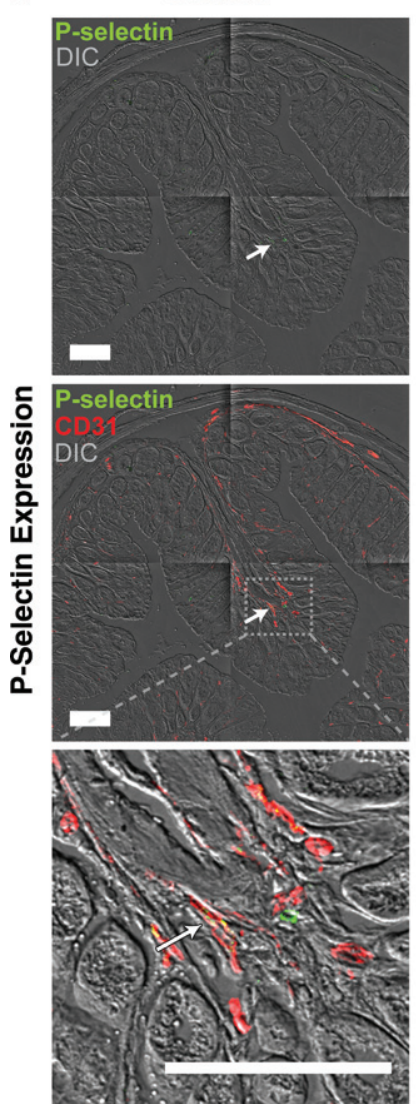

TNBS Day 1
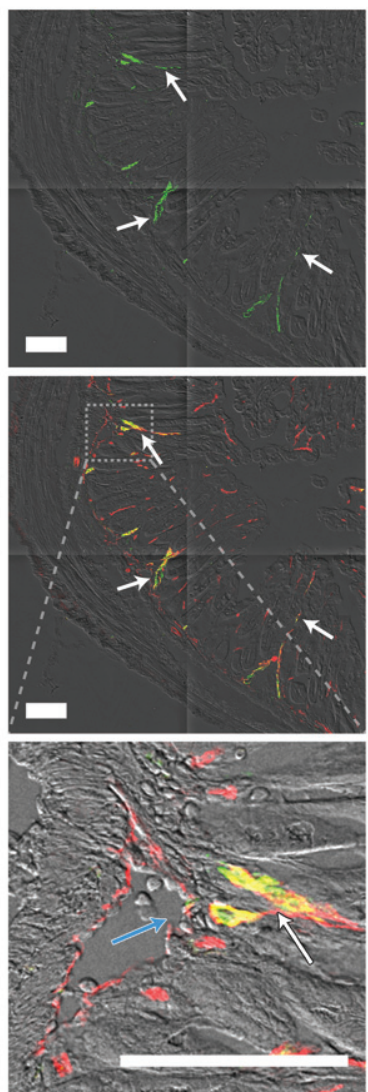

TNBS Day 5
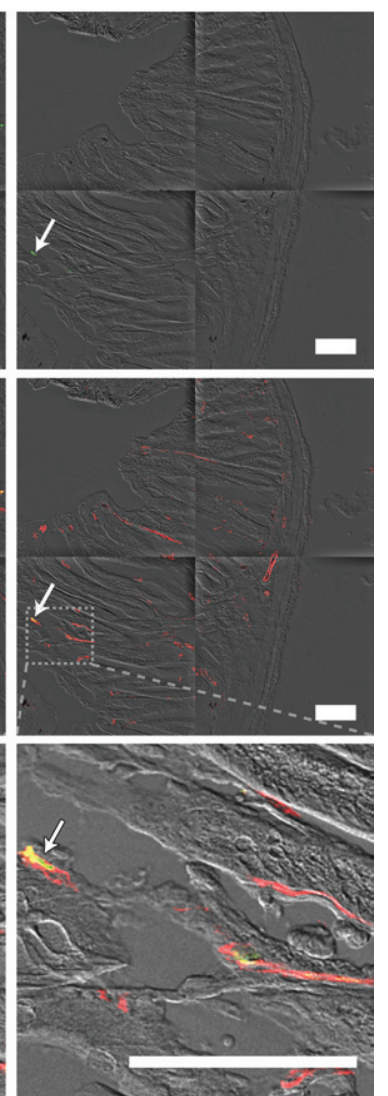

Figure 3: $\quad \mathrm{P}$ - and E-selectin expression in the colon of control mice and experimental mice after TNBSinduced colitis. Representative tiled confocal micrographs of, $A$, P-selectin (green) (white arrows) and CD31 (red) overlaid on differential interference contrast (DIC) images show expression of both $\mathrm{P}$ - and $\mathrm{E}$-selectin in capillaries of the colonic wall in a control mouse and in experimental mice at days 1 and 5 after induction of acute colitis. The area where immune cells have accumulated around P- or E-selectin-positive vessels (blue arrow) is shown. Gray boxes indicate the area that was enlarged. P-selectin expression could be observed within vessels extending through the mucosa, whereas E-selectin expression was mainly restricted to vessels at the base of the mucosa (scale bar $=100 \mu \mathrm{m}$ ). Note minimal expression in the control mouse. (Fig 3 continues.) day 1 (Fig $2, B)$. To confirm that MBSelectin was binding to inflamed vascular endothelium within the colon, MBs were fluorescently labeled prior to injection and visualized by using confocal microscopy. Consistent with the in vivo US imaging results, labeled $\mathrm{MB}_{\text {Selectin }}$ accumulated within capillaries in the mucosa of day-1 TNBS-induced mice (Fig $2, C)$, whereas in day-5 TNBS-induced mice there was only minimal accumulation (Fig 2, C). In control mice, no $\mathrm{MB}$ accumulation was observed (Fig 2, C).

Consistent with the findings of US and fluorescently labeled MB accumulation, immunofluorescent staining of colons revealed that both $\mathrm{P}$ - and E-selectin expression levels in vessels were significantly higher at day 1 after induction of acute colitis $(34.2 \% \pm 18.9$ of vessels were positive for $\mathrm{P}$-selectin, $32.1 \% \pm$ 26.2 of vessels were positive for $\mathrm{E}$-selectin; $P=.004$ and $P=.014$, respectively) and were significantly lower at day $5(7.5 \% \pm 5.8$ for P-selectin, $5.8 \%$ \pm 5.6 for E-selectin; $P=.0002$ and $P=$ .0038 , respectively) than those in control mice (Fig 3, $A$ and $B$ ). There was no significant difference between colons in control mice and colons in day5 mice in $\mathrm{P}$ - or E-selectin expression $(P=.40$ and $P=0.96$, respectively $)$. Qualitative assessment of both P- and E-selectin distribution revealed that vessels at the base of the mucosa were most often positive for both $\mathrm{P}$ - and $\mathrm{E}$ selectin, while vessels that extended deep into the mucosa were seldom positive for E-selectin (Fig 3, $A$ and $B$ ). The vessels that stained positive for $\mathrm{P}$ - and E-selectin were often in close proximity to immune cells present in the submucosa and the base of the mucosa (Fig $3, A$ and $B$ ). Mean histologic scoring of inflammation significantly increased at day $1(3.0 \pm 1.0)$ compared with that in control mice $(0 \pm 0, P<.001)$ and significantly decreased in day-5 mice $(1.5$ $\pm 0.7, P<.001)$.

In vivo blocking experiments enabled us to further confirm binding specificity of $\mathrm{MB}_{\text {Selectin }}$ to both $\mathrm{P}$-selectin and E-selectin. When anti-P-selectin antibodies were administered first, US imaging signal decreased by $66 \%$ and decreased a further $20 \%$ when 
Figure 3 (continued)

B
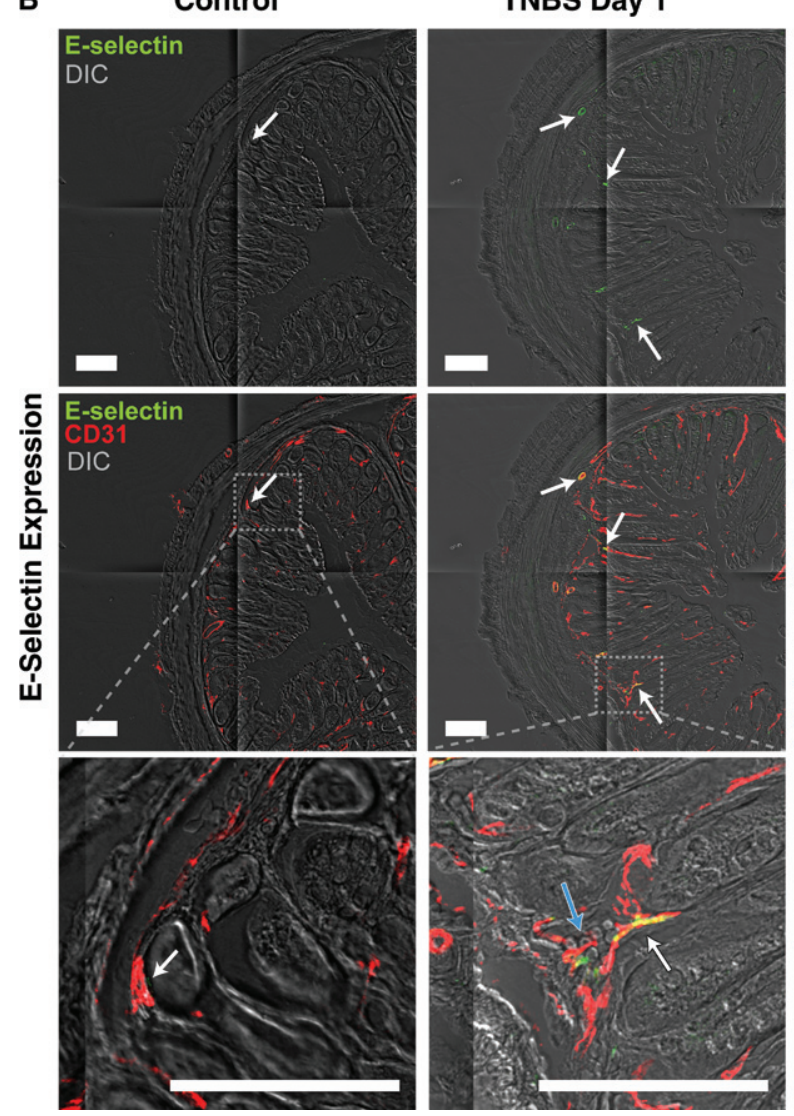

Figure 3: (continued). Representative tiled confocal micrographs of, B, E-selectin (green) (white arrows) and CD31 (red) overlaid on differential interference contrast (DIC) images show expression of both P- and E-selectin in capillaries of the colonic wall in a control mouse and in experimental mice at days 1 and 5 after induction of acute colitis. The area where immune cells have accumulated around P- or E-selectin-positive vessels (blue arrow) is shown. Gray boxes indicate the area that was enlarged. P-selectin expression could be observed within vessels extending through the mucosa, whereas E-selectin expression was mainly restricted to vessels at the base of the mucosa (scale bar $=100 \mu \mathrm{m}$ ). Note minimal expression in control mouse.

compared with baseline after anti-Eselectin administration (overall imaging signal decreased by $86 \%, P=.02$ ). When anti-E-selectin antibodies were administered first, US imaging signal decreased by $56 \%$ and decreased a further 29\% after anti-P-selectin antibody administration (overall imaging signal decreased by $85 \%, P=.02$ ). Sequential decrease of in vivo US imaging signal after subsequent administration of both anti-P-selectin and anti-E-selectin antibodies suggested overexpression of both receptors. Similarly, US imaging significantly decreased $(P=.01)$ by a total of $88 \%$ with rPSGL-Ig-conjugated liposomes (Fig 4, A) and did not change significantly $(P=.53)$ with control liposomes. Consistent with the in vivo imaging results after blocking, day 1 TNBS-induced mice that were incubated with fluorescently labeled rPSGLIg-conjugated liposomes did not accumulate labeled $\mathrm{MB}_{\text {Selectin }}$ in the colon (Fig 4, B).

\section{Quantitative Correlation of Selectin- targeted US Findings with FDG PET/CT Findings}

FDG PET/CT was performed on the same day as US to quantitatively correlate FDG uptake with $\mathrm{MB}_{\text {Selectin }}$ retention at sites of bowel inflammation in a cross-modality intraanimal comparison. Similar to US findings, there was low mean tracer uptake in the colon of control mice $(2.6 \% \mathrm{ID} / \mathrm{g} \pm 1.3$; range, $0.4 \%-4.4 \%$ ID $/ \mathrm{g}$ ) (Fig 5). In mice with low-grade colitis at day 1 , mean tracer uptake significantly $(P<.001)$ increased to $8.3 \% \mathrm{ID} / \mathrm{g} \pm 4.1$ (range, $3.6 \%-17.7 \% \mathrm{ID} / \mathrm{g})$. In mice with lowgrade colitis at day 5 , tracer uptake (mean, $3.8 \% \mathrm{ID} / \mathrm{g} \pm 1.6$; range, $0.5 \%$ $6.8 \% \mathrm{ID} / \mathrm{g})$ was significantly $(P<.001)$ lower than that in the mice scanned at day 1. Overall, there was strong correlation between US signal and FDG tracer uptake on PET/CT images $(\rho=$ $0.89, P<.001)$.

\section{Discussion}

This study showed that US imaging performed with clinically translatable $\mathrm{MB}_{\text {Selectin }}$ functionalized with rPSGL-Ig enables visualization and quantification of inflammation within the colon in a murine acute colitis model. Cross-modality intraanimal comparison revealed that US imaging with $\mathrm{MB}_{\text {Selectin }}$ correlated well with FDG uptake at PET/CT.

Chronic inflammatory diseases, such as IBD, are characterized by inappropriate and sustained recruitment of inflammatory cells into affected tissues, resulting in chronic tissue damage and loss of function $(26,27)$. Leukocyte migration from the blood into inflamed tissue across the wall of postcapillary venules is mediated by multiple adhesion molecules. These allow leukocytes to firmly adhere to the endothelial cells of inflamed vasculature and eventually migrate toward inflammatory foci (28). At the beginning of this multistep leukocyte adhesion cascade, rolling of leukocytes along vascular endothelial cells (which increases the exposure time of leukocytes with endothelial cell surface proteins) is mediated by selectins, including $\mathrm{P}-$, E-, and L-selectin. While L-selectin is expressed by most leukocytes, both $\mathrm{P}$-selectin and E-selectin are expressed by inflamed vascular endothelial cells and are considered the most important molecules for leukocyte rolling (28). P-selectin is stored 


\section{Figure 4}
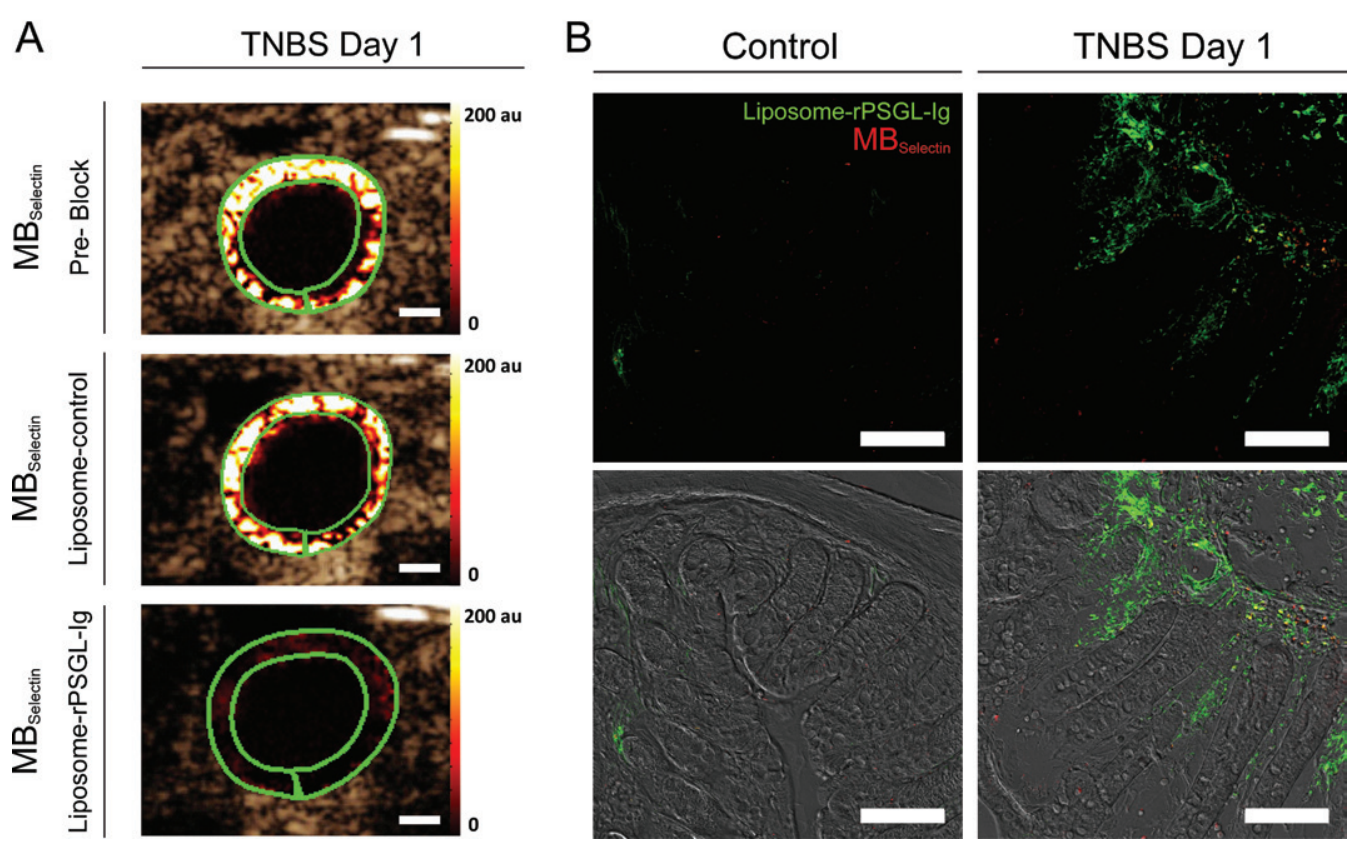

Figure 4: In vivo blocking of $\mathrm{MB}_{\text {Selectin }}$ binding. $A$, Representative transverse selectin-targeted US images of the colon in a mouse at day 1 after colitis induction. High US signal with $\mathrm{MB}_{\text {Selectin }}$ is seen prior to addition of the rPSGL-Ig-conjugated liposome blocking agent (top) and after addition of a nontargeted control liposome (middle). US signal with use of $\mathrm{MB}_{\text {Selectin }}$ significantly decreased after in vivo administration of the rPSGL-Ig-conjugated liposome blocking agent (bottom) (scale bar = $1 \mathrm{~mm}$ ). $B$, Confocal micrographs of colitis tissue after administration of fluorescently labeled $\mathrm{MB}_{\text {Selectin }}$ (red) and blocking rPSGL-lgconjugated liposome (green). Consistent with in vivo US imaging results shown in $A$, there was only minimal accumulation of $\mathrm{MB}_{\text {Selectin }}$ in mice at day 1 after colitis induction (right panel) (scale bar, $100 \mu \mathrm{m}$ ). Note low accumulation of rPSGL-Ig-conjugated liposome and $\mathrm{MB}_{\text {Selectin }}$ in control noninflamed colon tissue (left).

in secretory vesicles called Weibel-Palade bodies and, after acute activation with inflammatory mediators (including tumor necrosis factor $\alpha$, histamine, thrombin, and complement C5a), is trafficked to the cell surface within minutes. This initial trafficking of $\mathrm{P}$ selectin to the cell surface is followed by de novo synthesis and expression of P-selectin by the activated endothelial cells 4-5 hours later $(29,30)$. Vascular endothelial cell expression of E-selectin is entirely under transcriptional control, and cell surface expression can be detected approximately 2 hours after acute stimulation $(29,31,32)$. In patients with IBD, both $\mathrm{P}$-selectin and E-selectin have been shown to be constitutively expressed on inflamed vascular endothelium during the active phase of the disease (7,33-35). Thus, both markers could be further evaluated as promising imaging biomarkers with which to monitor disease activity and progression in patients with IBD.

In our study, we explored whether US imaging with selectin-targeted MB could be developed for use in the noninvasive assessment of inflammation. The P- and E-selectin ligand rPSGL-Ig, which is currently in clinical trials (11), was covalently bound to the shell of a blood pool US contrast agent to design a clinically translatable selectin-targeted contrast agent $\mathrm{MB}\left(\mathrm{MB}_{\text {Selectin }}\right)$ for US imaging of inflammation. We first assessed the in vitro binding characteristics of $\mathrm{MB}_{\text {Selectin }}$ to human and murine $\mathrm{P}$ - and E-selectin. Cross-reactivity of $\mathrm{MB}_{\text {Selectin }}$ to human and murine selectins was confirmed by using control MB and blocking studies, resulting in decreased attachment of $\mathrm{MB}_{\text {Selectin }}$ to murine and human selectins. Interestingly, while Pand E-selectin primarily mediate rolling of leukocytes on endothelial cells, most MBs firmly attached to the four different recombinant proteins (human and murine $\mathrm{P}$ - and E-selectins) under flow shear stress conditions and showed only minimal rolling in our experiments. Possible explanations for this observation may include the different size of $\mathrm{MB}_{\text {Selectin }}$ compared with leukocytes (1-2 $\mu \mathrm{m}$ for $\mathrm{MB}_{\text {Selectin }}$ vs 12-15 $\mu \mathrm{m}$ for leukocytes) (36), which reduces the dislodging force imposed on the MB by blood flow, as well as differences in ligand surface density (approximately 3000 per square micrometer on $\mathrm{MB}_{\text {Selectin }}$ vs 400 per square micrometer on leukocytes) (37) that may influence the overall avidity of the MB-ligand complex.

Since $\mathrm{MB}_{\text {Selectin }}$ was able to specifically bind $\mathrm{P}$ - and E-selectin in vitro, we tested whether it could be used to visualize and quantify inflammation in vivo by using a well-established chemically 
Figure 5
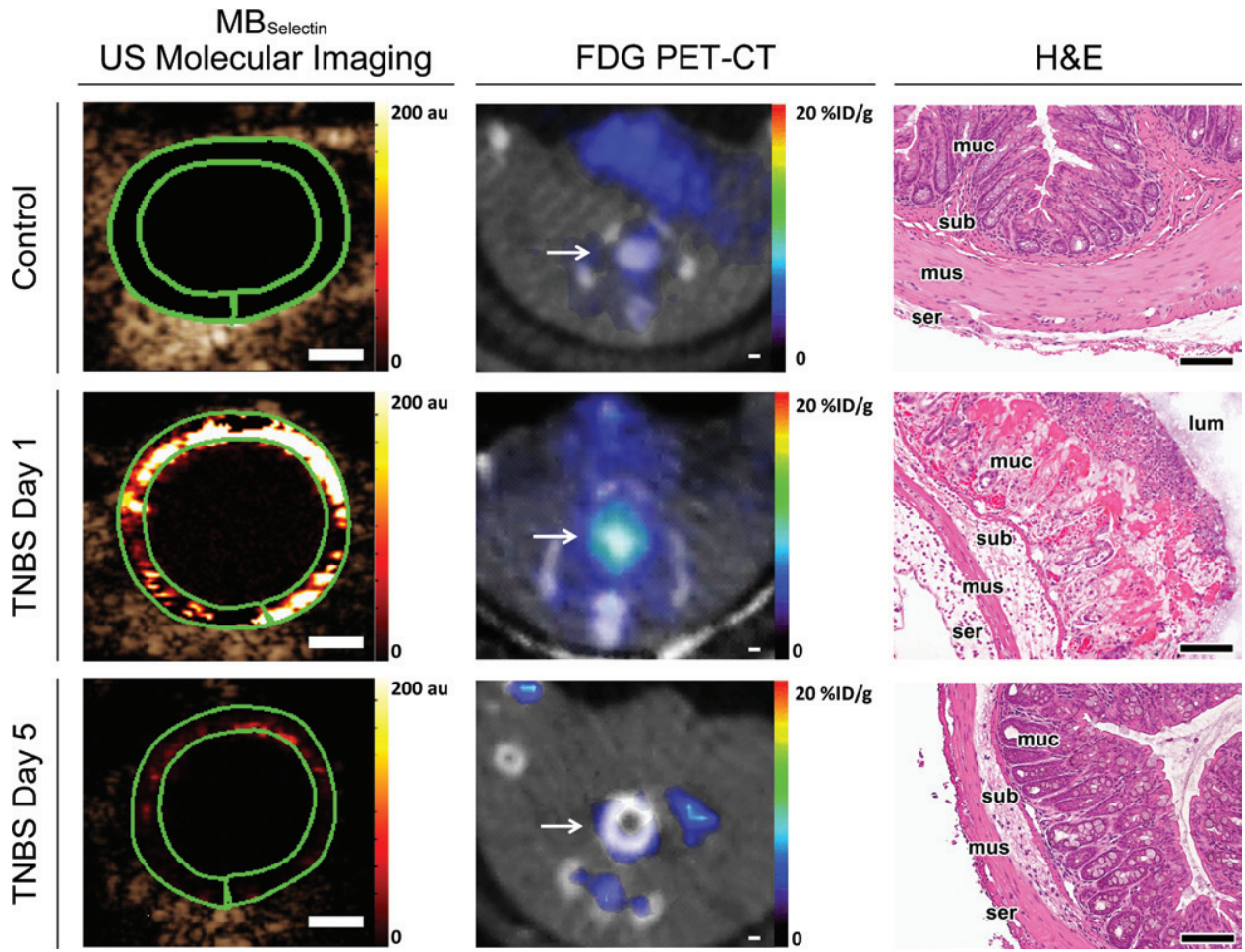

Figure 5: Cross-modality intraanimal comparison of selectin-targeted US images and FDG PET/CT images in control mice and mice with colitis at days 1 and 5 after TNBS administration. Representative transverse US images (left) and PET/CT images (middle) (arrows = contrast agent-filled colon) show background signal in control mouse (top) and increased signal at day 1 after colitis induction (middle). At day 5 (bottom), both US signal and PET/CT FDG uptake substantially decreased when compared with those at day 1 (scale bar, $1 \mathrm{~mm}$ ). In vivo imaging findings were compared with degree of inflammation assessed on hematoxylin-eosin-stained colon slices (right). Corresponding colon in control mouse (top) shows intact viable folded mucosa (muc) with regularly spaced glands of uniform height, thin submucosal layer (sub), thick muscular wall (mus), and flattened serosa (ser) with lack of observable inflammation. Corresponding colon of the mouse at day 1 (middle) shows marked necrosis of entire mucosa, with concomitant edema and hemorrhage, marked neutrophil exudation into colonic lumen (lum), inflammation and edema that expand and thicken the submucosa and serosa, and relative thinning of the muscular wall, with mild inflammation and patchy necrosis. Corresponding colon of the mouse at day 5 (bottom) shows only mild inflammation and edema expanding and thickening the lamina propria of mucosa and submucosa. In addition, there is mild loss of glands in the mucosa. (Original magnification, $\times 200$, scale bar $=100 \mu \mathrm{m}$.)

induced murine model of colitis after rectal administration of ethanol and TNBS. We observed minimal signal in the normal noninflamed bowel, a significant increase in the signal 1 day after induction of acute colitis, and a significantly reduced signal by day 5 , with lower grades of colitis. In vivo imaging findings were paralleled by $\mathrm{P}$ - and $\mathrm{E}$ selectin expression levels and histologic grades of inflammation. These data suggest that $\mathrm{MB}_{\mathrm{s}}$ be used as a noninvasive biomarker of inflammation in murine colitis.

To further validate selectin-targeted US imaging as a quantitative tool for inflammation assessment in IBD, we performed a cross-modality intraanimal comparison of US imaging with FDG PET/CT. FDG PET/CT is a wellestablished quantitative molecular imaging tool that is widely used clinically in patients who have a disease with increased glucose metabolism, such as cancer, inflammation, or infection. Several clinical studies have shown that FDG uptake correlates well with disease activity in patients with IBD (38-40). In murine colitis models, it has been shown that FDG uptake was specifically correlated with glucose transporter 1 expression by $\mathrm{CD}^{+} \mathrm{T}$ cells, and those cells were identified as the major cellular source of FDG uptake in murine colitis (20). Our study showed strong correlation between selectin-targeted 
US signal and FDG uptake at PET/ CT in terms of inflammation quantification in murine colitis. This correlation between US and PET/CT could be observed over a large spectrum of inflammation grades, suggesting that selectin-targeted US molecular imaging may yield quantitative information over a continuum of disease severity, which is important if this technique is to be further developed for clinical monitoring of disease activity in patients with IBD. Although the molecular imaging targets are different for both imaging approaches (glucose transporter 1 on $\mathrm{CD}^{+}{ }^{+} \mathrm{T}$ cells vs $\mathrm{P}$ - and E-selectin on inflamed vascular endothelium), the strong correlation of US with a highly quantitative molecular imaging tool such as FDG PET/CT is encouraging and highlights the potential of selectintargeted US imaging quantitation of disease processes, such as acute inflammation from IBD at the molecular level.

Our study had recognized limitations. While the TNBS-induced IBD model is advantageous in terms of the spectrum of disease grades among different mice and varies over a short period of time due to the spontaneous recovery of most mice, it does not fully reflect all disease states in patients with IBD. Also, inflammation is limited to the colon; thus, it does not model smallbowel involvement. However, since the mechanism of leukocyte recruitment is mediated through the same cascade in different organs, we expect similar results for small-bowel inflammation imaging and in animals with acute bouts of inflammation on the background of chronic inflammatory changes. Furthermore, while this imaging strategy looks promising in mice, there may be challenges associated with scaling this approach from small to large animals and eventually to patients; these challenges include the need to scan a larger field of view, motion artifacts from bowel movements, and sensitivity issues when performing US imaging of deeper tissues when compared with the setting in mice. Further improvements in US software and hardware, including three-dimensional capabilities that will enable scanning of extended anatomic areas, are needed to make this promising imaging technique a clinically relevant tool.

In conclusion, our results suggest that selectin-targeted US imaging with clinically translatable $\mathrm{MB}_{\text {Selectin }}$ functionalized with rPSGL-Ig enables quantification of inflammation at the molecular level in an acute model of IBD in mice. By using a truncated version of the naturally expressed P-selectin glycoprotein ligand 1 as a binding ligand, $\mathrm{MB}_{\mathrm{S}}$ attachment uses the natural pathway of leukocyte recruitment to inflamed tissue and may be further developed as a noninvasive imaging biomarker for inflammation quantification.

Since US is widely available, relatively inexpensive, and free of radiation, US imaging with $\mathrm{MB}_{\text {Selectin }}$ is a promising potentially clinically translatable alternative approach for objective quantification of inflammation in IBD.

Acknowledgments: We thank Frederick Chin, $\mathrm{PhD}$, and the Stanford Cyclotron Facility team for preparation of FDG. We also acknowledge the technical support by Timothy Doyle, PhD from the Small Animal Imaging Facility at Stan ford University.

\section{Disclosures of Conflicts of Interest: H.W. No} relevant conflicts of interest to disclose. S.M. No relevant conflicts of interest to disclose. T.B. Financial activities related to the present article: none to disclose. Financial activities not related to the present article: is employed by Bracco Suisse. Other relationships: none to disclose. A.M.L. No relevant conflicts of interest to disclose. R.L. No relevant conflicts of interest to disclose. P.B. Financial activities related to the present article: none to disclose. Financial activities not related to the present article: is employed by Bracco Suisse. Other relationships: none to disclose. S.S.G. Financial activities related to the present article: none to disclose. Financial activities not related to the present article: is on the board of Albatross Medical Imaging, Endra, General Electric, ImaginAb, MagArray, MiLabs, ReflXion Medical, Varian Medical, VisualSonics/Sonosite, and Enlight; is a consultant to CytomX Therapeutics, NinePoint Medical, Spectrum Dynamics, and Bracco Diagnostics; gave lectures for Bracco Diagnostics and Aspect Imaging; holds stock in Cellsight, Endra, Enlight, ImaginAb, Lumen Therapeutics, MagArray, NinePoint Medical, Prolume, RefleXion Medical, Spectrum Dynamics, and VisualSonics/Sonosite; institution received grants from Bayer Healthcare Pharmaceuticals, General Electric, and Sanofi-Aventis. Other relationships: none to disclose. F.T. Financial activities related to the present article none to disclose. Financial activities not related to the present article: is employed by Bracco Suisse. Other relationships: none to disclose L.T. No relevant conflicts of interest to disclose. J.K.W. Financial activities related to the pre sent article: none to disclose. Financial activities not related to the present article: is a consultant to Bracco Suisse. Other relationships: none to disclose.

\section{References}

1. Loftus EV Jr. Clinical epidemiology of inflammatory bowel disease: incidence, prev alence, and environmental influences. Gastroenterology 2004;126(6):1504-1517.

2. Danese S. New therapies for inflammatory bowel disease: from the bench to the bedside. Gut 2012;61(6):918-932.

3. Baumgart DC, Carding SR. Inflammatory bowel disease: cause and immunobiology. Lancet 2007;369(9573):1627-1640.

4. Bachmann C, Klibanov AL, Olson TS, et al. Targeting mucosal addressin cellular adhesion molecule (MAdCAM)-1 to noninvasively image experimental Crohn's disease. Gastroenterology 2006;130(1):8-16.

5. Deshpande N, Lutz AM, Ren Y, et al. Quantification and monitoring of inflammation in murine inflammatory bowel disease with targeted contrast-enhanced US. Radiology 2012;262(1):172-180.

6. Barthel SR, Gavino JD, Descheny L, Dimitroff CJ. Targeting selectins and selectin ligands in inflammation and cancer. Expert Opin Ther Targets 2007;11(11):1473-1491.

7. Bhatti M, Chapman P, Peters M, Haskard D, Hodgson HJ. Visualising E-selectin in the detection and evaluation of inflammatory bowel disease. Gut 1998;43(1):40-47.

8. Lorant DE, Topham MK, Whatley RE, et al Inflammatory roles of P-selectin. J Clin Invest 1993;92(2):559-570.

9. Almulki L, Noda K, Amini R, et al. Surprising up-regulation of P-selectin glycoprotein ligand-1 (PSGL-1) in endotoxin-induced uveitis. FASEB J 2009;23(3):929-939.

10. Khor SP, McCarthy K, DuPont M, Murray K, Timony G. Pharmacokinetics, pharmacodynamics, allometry, and dose selection of rPSGL-Ig for phase I trial. J Pharmacol Exp Ther 2000;293(2):618-624.

11. Busuttil RW, Lipshutz GS, Kupiec-Weglinski JW, et al. rPSGL-Ig for improvement of early liver allograft function: a double-blind, placebo-controlled, single-center phase II study. Am J Transplant 2011;11(4):786-797.

12. Bettinger T, Bussat P, Tardy I, et al. Ultrasound molecular imaging contrast agent 
binding to both $\mathrm{E}$ - and P-selectin in different species. Invest Radiol 2012;47:516-523.

13. Davidson BP, Kaufmann BA, Belcik JT, Xie A, Qi Y, Lindner JR. Detection of antecedent myocardial ischemia with multiselectin molecular imaging. J Am Coll Cardiol 2012; 60(17):1690-1697.

14. Wirtz S, Neufert C, Weigmann B, Neurath MF. Chemically induced mouse models of intestinal inflammation. Nat Protoc 2007;2(3):541-546.

15. Bouma G, Strober W. The immunological and genetic basis of inflammatory bowel disease. Nat Rev Immunol 2003;3(7):521-533.

16. te Velde AA, Verstege MI, Hommes DW. Critical appraisal of the current practice in murine TNBS-induced colitis. Inflamm Bowel Dis 2006;12(10):995-999.

17. Shen C, de Hertogh G, Bullens DM, et al. Remission-inducing effect of anti-TNF monoclonal antibody in TNBS colitis: mechanisms beyond neutralization? Inflamm Bowel Dis 2007;13(3):308-316.

18. Izzo AA, Mascolo N, Borrelli F, Capasso F. Defaecation, intestinal fluid accumulation and motility in rodents: implications of cannabinoid CB1 receptors. Naunyn Schmiedebergs Arch Pharmacol 1999;359(1):65-70.

19. Borrelli F, Capasso F, Capasso R, et al. Effect of Boswellia serrata on intestinal motility in rodents: inhibition of diarrhoea without constipation. Br J Pharmacol 2006;148(4): 553-560.

20. Klibanov AL, Rychak JJ, Yang WC, et al. Targeted ultrasound contrast agent for molecular imaging of inflammation in high-shear flow. Contrast Media Mol Imaging 2006;1(6): 259-266.

21. Willmann JK, Cheng Z, Davis C, et al. Targeted microbubbles for imaging tumor angiogenesis: assessment of whole-body biodistribution with dynamic micro-PET in mice. Radiology 2008;249(1):212-219.
22. Brewer S, McPherson M, Fujiwara D, et al. Molecular imaging of murine intestinal inflammation with 2-deoxy-2-[18F]fluoro-Dglucose and positron emission tomography. Gastroenterology 2008;135(3):744-755.

23. Kaufmann BA, Carr CL, Belcik JT, et al. Molecular imaging of the initial inflammatory response in atherosclerosis: implications for early detection of disease. Arterioscler Thromb Vasc Biol 2010;30(1):54-59.

24. Kojouharoff G, Hans W, Obermeier F, et al. Neutralization of tumour necrosis factor (TNF) but not of IL-1 reduces inflammation in chronic dextran sulphate sodium-induced colitis in mice. Clin Exp Immunol 1997;107(2): 353-358.

25. Rachmilewitz D, Karmeli F, Takabayashi K, et al. Immunostimulatory DNA ameliorates experimental and spontaneous murine colitis. Gastroenterology 2002;122(5):14281441.

26. Rivera-Nieves J, Gorfu G, Ley K. Leukocyte adhesion molecules in animal models of inflammatory bowel disease. Inflamm Bowel Dis 2008;14(12):1715-1735.

27. Ghosh S, Panaccione R. Anti-adhesion molecule therapy for inflammatory bowel disease. Therap Adv Gastroenterol 2010;3(4): 239-258.

28. Ley K, Laudanna C, Cybulsky MI, Nourshargh S. Getting to the site of inflammation: the leukocyte adhesion cascade updated. Nat Rev Immunol 2007;7(9):678-689.

29. Eppihimer MJ, Wolitzky B, Anderson DC, Labow MA, Granger DN. Heterogeneity of expression of E- and P-selectins in vivo. Circ Res 1996;79(3):560-569.

30. Homeister JW, Zhang M, Frenette PS, et al. Overlapping functions of $\mathrm{E}$ - and $\mathrm{P}$-selectin in neutrophil recruitment during acute inflammation. Blood 1998;92(7):2345-2352.

31. Henseleit U, Steinbrink K, Goebeler M, et al. E-selectin expression in experimental models of inflammation in mice. J Pathol 1996; 180(3):317-325.

32. Labow MA, Norton CR, Rumberger JM, et al. Characterization of E-selectin-deficient mice: demonstration of overlapping function of the endothelial selectins. Immunity 1994 . 1(8):709-720.

33. Schürmann GM, Bishop AE, Facer P, et al. Increased expression of cell adhesion molecule P-selectin in active inflammatory bowel disease. Gut 1995;36(3):411-418.

34. Jubeli E, Moine L, Vergnaud-Gauduchon J, Barratt G. E-selectin as a target for drug delivery and molecular imaging. J Control Release 2012;158(2):194-206.

35. Magro F, Araujo F, Pereira P, Meireles E, Diniz-Ribeiro M, Velosom FT. Soluble selectins, sICAM, sVCAM, and angiogenic proteins in different activity groups of patients with inflammatory bowel disease. Dig Dis Sci 2004;49(7-8):1265-1274.

36. Selz KA. A third measure-metastable state in the dynamics of spontaneous shape change in healthy human's white cells. PLOS Comput Biol 2011;7(4):e1001117.

37. Norman KE, Katopodis AG, Thoma G, et al. $\mathrm{P}$-selectin glycoprotein ligand-1 supports rolling on E- and P-selectin in vivo. Blood 2000; 96(10):3585-3591 .

38. Chandler MB, Zeddun SM, Borum ML. The role of positron emission tomography in the evaluation of inflammatory bowel disease. Ann N Y Acad Sci 2011;1228:59-63.

39. Jacene HA, Ginsburg P, Kwon J, et al. Prediction of the need for surgical intervention in obstructive Crohn's disease by 18F-FDG PET/CT. J Nucl Med 2009;50(11):17511759.

40. Louis E, Ancion G, Colard A, Spote V, Belaiche J, Hustinx R. Noninvasive assessment of Crohn's disease intestinal lesions with (18)F-FDG PET/CT. J Nucl Med 2007;48(7): 1053-1059. 